\title{
The pernicious effect of retroactive changes in the Code: Darevskia and nomenclatorial stability, a reply to Busack et al. (2016)
}

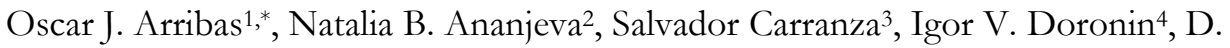 \\ James Harris ${ }^{5}$, Nikolay L. Orlov ${ }^{6}$, Valentina F. Orlova ${ }^{7}$
}

1 Avda. Fco. Cambó 23; 08003 Barcelona, Spain.

2 Zoological Instutute RAS, Universitetskaja nab. 1, St.Petersburg, Russia, 199034.

${ }^{3}$ Institute of Evolutionary Biology (CSIC - Universitat Pompeu Fabra), Passeig Marítim de la Barceloneta 37-49, 08003 Barcelona, Spain.

${ }_{4}^{4}$ Zoological Instutute RAS, Universitetskaja nab. 1, St.Petersburg, Russia, 199034.

${ }_{5}^{5}$ Centro de Investigação em Biodiversidade e Recursos Genéticos (CIBIO/UP), Campus Agrario de Vairao, 4485-661 Vila do Conde, Portugal.

${ }^{6}$ Zoological Instutute RAS, Universitetskaja nab. 1, St.Petersburg, Russia, 199034.

${ }^{7}$ Zoological Museum of M.V. Lomonosov State University, Bolshaya Nikitskaya Str. 6, Moscow, Russia, 125009.

*Correspondence: Phone: + 34 656470234, Email: oarribas@xtec.cat

Received: 09 January 2017; returned for review: 10 February 2017; accepted: 02 March 2017.

Busack et al. (2016) concluded that the name Darevskia should be attributed to Arribas (1999) instead of Arribas (1997), rendering the latter name a junior synonym of Caucasilacerta Harris et al. (1998). In this paper, we provide a detailed answer to Busack et al. (2016) and argue that Arribas (1997) fulfilled the publication requirements of the International Code of Zoological Nomenclature (ICZN) in place in 1997 and, therefore, Darevskia Arribas, 1997 is a valid name. In order to clarify this issue, a case has been submitted to the ICZN. To avoid unnecessary confusion in Old World Lacertid taxonomy, we recommend that until the commission rules on this case, Arribas (1997) should continue to be considered the authority of both Darevskia and Iberolacerta.

Key words: Caucasilacerta; Darevskia; Iberolacerta; ICZN; microfiche.

In a recent manuscript by Busack et al. (2016), these authors conclude that the name Darevskia should be attributed to Arribas (1999) instead of Arribas (1997), rendering this name as a junior invalid synonym of Caucasilacerta HARRIs, ARNOLD \& Thomas, 1998, which according to the authors is not a nomen nudum and should, therefore, replace Darevskia as the valid name of this genus. Additionally, BusAcK et al. (2016) consider that the publication describing the genus Iberolacerta is also Arribas (1999) instead of Arribas (1997). While we agree that there has been some confusion in the literature regarding the date that should be attributed for Darevskia (1997 or 1999), it is necessary to point out that the manuscript by BusAck et al. (2016) contains an important mistake: contrary to what they say, the name Darevskia was made available from the 1997 thesis when first published, since publications in microfiches were allowed in the 1985 edition of the International Code of Zoologi- 
cal Nomenclature (the Code hereafter), which was then in force. Busack et al. (2016) confuse microfiche with microfilm, the latter a forbidden method for publication of nomenclatural acts (see point 1 below). Darevskia Arribas, 1997 is currently unavailable, only because of a retroactive change in the Code introduced in the 1999 edition, which removed the possibility to publish names in microfiches. Because of this retroactive change between the 1985 and 1999 editions of the Code, an application has been made to the International Commission on Zoological Nomenclature (ICZN, Case 3711, in revision, to be published in the Bulletin of Zoological Nomenclature and voted), to make Darevskia Arribas 1997 available, and hence, to preserve this widely used name over the hardly ever used name Caucasilacerta Harris, Arnold \& Thomas, 1998.

We, therefore, urge the scientific community to refrain from using Caucasilacerta. The conclusions of BusacK et al. (2016) would seriously disrupt communication in Old World Lacertid taxonomy, if they are followed. First, the Committee has to rule on case 3711 (and the prevailing use maintained in the meantime; Art 82.1 of the Code), deciding if Arribas (1997) (microfiche publication) or ARribAs (1999) (paper publication) is the valid description of both Iberolacerta and Darevskia. Furthermore, arguments have been presented suggesting that Caucasilacerta should be considered a nomen nudum (see Arribas, 2016).

We provide below, a detailed answer to BusACK et al. (2016) to clarify several issues:

1) Arribas (1997) was valid when published in 1997, because microfiche was a

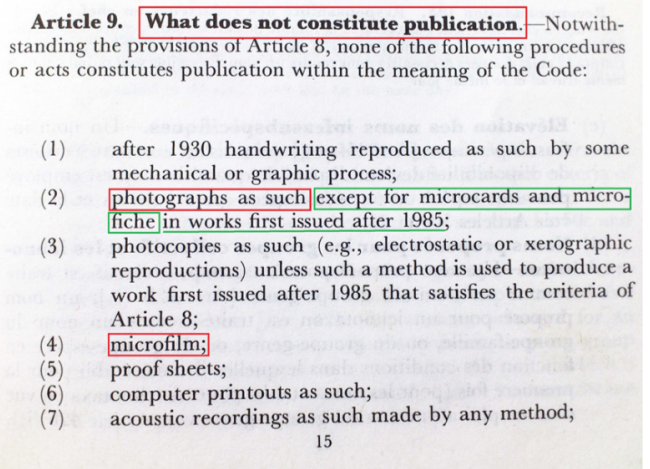

Figure 1: Reproduction of Art. 9 of the 1985 edition of the Code in which it can be seen that it clearly distinguished microfiche from photographs [Article 9(2)] and microfilms [Article 9(4)], allowing microfiche but forbidding the use of photographs and microfilms as valid methods for publication of nomenclatorial acts.

valid publication form (although not recommended) in the former Code (see Recommendation $8 \mathrm{~A}$. in the 1985 Code edition). Also, they clearly distinguished microfiche from photographs and microfilms that according to Article 9(2) and 9(4) (ICZN, 1985) (Fig. 1) were not considered valid methods for publication of nomenclatorial acts: “(2) photographs as such except for microcards and microfiche in works first issued after 1985" and "(4) microfilm" (Art. 9(4); ICZN, 1985). As can be seen, the distinction between microfiche and microfilms was clear in the 1985 edition of the Code. Microfiche stopped being allowed in the 1999 version of the code (now in force) and in its amendments (Art 8.4; 1999, 2008, 2012), only paper and optical disks are allowed as physical support for publication of nomenclatorial acts. Nevertheless, it is not explicitly for- 
bidden (it is not mentioned among the currently forbidden methods as it is, for instance, for microfilm, Art 9.4; ICZN, 1999, 2008 , 2012). Retroactive changes in the current Code are a problem that should be corrected in future versions of the Code (eg. Duвois, 2010). Such problems are usually resolved by the Commission through its plenary powers by means of applications submitted (as in this case).

2) Arribas (1997) is a valid publication, as it was published with an ISBN reference (ISBN 84-490-0830-1). The publication was produced with the purpose of permanent record and distribution (Art 8.1; ICZN, $1985,1999,2008,2012$ ), and must be differentiated from unpublished versions of Oscar Arribas' PhD Thesis (Arribas, 1996), distributed to the members of the Thesis defense committee in December 1996, that obviously is not a publication (in the sense of the Example of Art. 9; ICZN, 1999, 2008, 2012 or Art 9(11) ICZN, 1985). The unpublished copy of the PhD Thesis shown in Fig. 2 of Busack et al. (2016), deposited in the University Library of the Universitat Autònoma de Barcelona on the $11^{\text {th }}$ of March 1997, was part of the bureaucratic procedure for a $\mathrm{PhD}$ Thesis defense done in November 1996 (as can be seen in the external and internal covers shown in Fig. 2 of Busack et al., 2016). There are even some minor differences with the final $\mathrm{PhD}$ Thesis defended in December 1996 (also unpublished in the sense of the Code) and obviously, with the published one as a book in microfiche in the following year (ARribas, 1997).

3) The publication of the $\mathrm{PhD}$ Thesis (Arribas, 1997; ISBN 84-490-0830-1) was produced and distributed by the Universi- tat Autònoma de Barcelona, and exchanged with other University libraries and institutions (a minimum of 19 copies in 17 Universities or Museums; see "Institutional Holdings of Arribas' Thesis" in Busack et al., 2016). Moreover, Arribas (1997) publication containing the PhD Thesis was available by purchase (Art 8(a); ICZN, 1985; Art 8.1; ICZN, 1999, 2008, 2012) in the following address: http:// publicacions.uab.es/tesis/fitxa_web.asp? $\mathrm{ID}=482$, where it appears catalogued as a microfiche (microfitxa in Catalan) at a price of $13.34 €$. The author received 12 copies that were distributed as a courtesy to several other European Lacertid specialists from Spain (Dr. Pedro Galan; Universidad de Coruña), Italy (Dr Gaetano Odierna, Universita degli Studi di Napoli; Dr. Ettore Olmo, Università di Ancona), the United Kingdom (Dr. E.N. Arnold; Natural History Museum, London), Austria (Dr. Josef Eiselt and Dr. Werner Mayer, Naturhistorisches Museum Wien), Germany (Dr. Wolfgang Böhme, Zoologische Museum Alexander Koenig, Bonn; Josef Schmidtler, München) and Russia (Dr. Ilya S. Darevsky, Russian Academy of Sciences, S. Petersburg).

4) Arribas (1997) PhD publication in microfiche includes, in addition to the new names, the statement of being a nomenclatorial act (gen. nov.) (Art 8.5.2; ICZN, 1985), the type species, complete diagnoses of both genera, all accepted species within each genus, derivatio nominis, distribution, detailed description and biogeography. The Arribas (1997) PhD publication in microfiche can be read in a microfiche viewer (usually present in libraries), but can also be easily read using a stere- 
omicroscope (binocular loupe). A facsimiled pdf scan of the whole publication (paper and microfiche) can be download from: https:// www.academia.edu/28266852/Morfolog\% C3\%ADa_filogenia_y_biogeograf\%C3\% ADa_de_las_lagartijas_de_alta_monta $\%$ C3\%B1a_de_los_Pirineos.

5) There is an Application submitted to the Commission (Case 3711) in April 2016, to be published in the Bulletin of Zoological Nomenclature, concerning the original publication of Iberolacerta and Darevskia. In this Application, we request to officially validate, in use of its plenary powers, ARRIBAS (1997) publication in microfiche as the nomenclatorial source for both names, because they were available when first published, even if not according with the Code currently in force. Pending potential publication in the Bulletin of Zoological Nomenclature for public evaluation of the case, we recommend that in the meantime (avoiding more confusion), Arribas (1997) should be conserved provisionally as the authority for Iberolacerta and Darevskia instead of destabilizing the nomenclature and disrupting communication in Old World Lacertid taxonomy.

6) As recently suggested by Arribas (2016), Caucasilacerta may be considered a nomen nudum, since the paragraph regarding the diagnosis is at some distance from the nomenclatorial act, among other problems. If this is considered as such, Darevskia would remain the valid name for the group. Again therefore, avoiding the use of Caucasilacerta seems preferable to prevent taxonomic instability, but this is still pending on the application presented to the Commission (Case 3711).
7) Iberolacerta has no synonymies and does not present nomenclatorial problems apart from the valid date of publication that is pending on a resolution by the ICZN (Case 3711). Therefore, regardless of the publication date of the genus' description, the name will still be Iberolacerta. Similarly, Pyrenesaura Arribas, 1999 (a subgenus of Iberolacerta) was described in the Russian Journal of Herpetology (Arribas, 1999), and is not affected by all these nomenclatorial disputes.

We applaud Busack et al. (2016) for their good intentions in attempting to resolve the confusion in the literature regarding the correct description date for Darevskia, and agree that authors need to be vigilant regarding potential synonyms for groups they intend to name. Nevertheless, we would like to also suggest that scientists who feel that widely used names need to be altered, should contact those involved prior to proposing name changes. In this way taxonomic instability may be avoided.

\section{References}

Arribas, O.J. (1996). Morfología, filogenia y biogeografía de las lagartijas de alta montaña de los Pirineos. Ph.D. Dissertation. Universidad Autónoma de Barcelona, Barcelona, Spain.

Arribas, O.J. (1997). Morfología, filogenia y biogeografía de las lagartijas de alta montaña de los Pirineos. Publications Universitat Autònoma Barcelona, Barcelona, Spain.

Arribas, O.J. (1999). Phylogeny and relationships of the Mountain lizards of Europe and Near East (Archaeolacerta Mertens, 1921 sensu lato) and their relationships among the Eurasian lacertid radiation. Russian Journal of Herpetology 6 (1): 1-22.

Arribas, O.J. (2016). Why Caucasilacerta Harris, Arnold \& Thomas, 1998 is a nomen nu- 
dum? Russian Journal of Herpetology 23 (4): 305-306.

Busack, S.D.; Salvador, A.; Bauer, A.M. \& KaISER, H. (2016). Darevskia and Iberolacerta (Reptilia, Lacertidae): Arribas, 1997 or 1999? The correct dating of two nomenclatural acts affecting Palearctic lizards, and validation of the name Caucasilacerta Harris, Arnold \& Thomas, 1998. Bionomina 10: 61-73.

Dubois, A. (2010). Retroactive changes should be introduced in the Code only with great care: problems related to the spellings of nomina. Zootaxa 2426: 1-42 .

Harris, D.J.; Arnold, E.N. \& Thomas, R.H. (1998). Relationships of lacertid lizards (Reptilia: Lacertidae) estimated from mitochondrial DNA sequences and morphology. Proceedings of the Royal Society 265: 19391948.

InTERNATIONAL COMMission OF ZoOLOGICAL Nomenclature (1985). International Code of Zoological Nomenclature adopted by the XX
General Assembly of the International Union of Biological Sciences, $3^{\text {rd }}$ ed. International Trust for Zoological Nomenclature, London.

INTERNATIONAL COMMISSION ON ZoOlogical Nomenclature (1999). International Code of Zoological Nomenclature, $4^{\text {th }} \mathrm{ed}$. The International Trust for Zoological Nomenclature, London.

InTERnATIONAL Commission ON Zoological Nomenclature (2008). Proposed Amendment of Articles 8, 9, 10, 21 and 78 of the International Code of Zoological Nomenclature to expand and refine methods of publication. Bulletin of Zoological Nomenclature 65: 265-275.

INTERNATIONAL COMMission ON Zoological Nomenclature (2012). Amendment of Articles $8,9,10,21$ and 78 of the International Code of Zoological Nomenclature to expand and refine methods of publication. Zootaxa 3450: 1-7. 